\section{Commentary: Thoracic endovascular aortic repair for uncomplicated acute type $B$ aortic dissection: It's not a complicated decision}

\author{
Bradley G. Leshnower, MD
}

The controversy regarding the optimal therapy for uncomplicated acute type B aortic dissection (UATBAD) remains unresolved. Thoracic endovascular aortic repair (TEVAR) is the undisputed gold standard for the treatment of complicated acute type B aortic dissection (cATBAD). However, there has not been widespread acceptance of the use of TEVAR for all patients with UATBAD due to the perceived excellent outcomes with optimal medical therapy (OMT) alone. While OMT provides excellent in-hospital and 1 -year survival, ${ }^{1}$ mortality significantly increases in the chronic phase due to false lumen aneurysm formation and rupture. A recent analysis of the Emory Aortic Database of 318 patients with uATBAD demonstrated that $46 \%$ of patients required intervention in the chronic phase, and intervention-free survival was only $49 \%$ and $31 \%$ at 5 and 10 years. $^{2}$ Therefore, TEVAR has been proposed as an adjunct to OMT, with the intent to remodel the dissected thoracic aorta and improve aortic-related mortality in the chronic phase, as demonstrated by the INSTEAD-XL (Investigation of Stent Grafts in Aortic Dissection with extended length of follow-up) data. ${ }^{3}$ The argument against the use of TEVAR for uATBAD includes subjecting patients to the periprocedural risks of stroke, retrograde type A dissection, device cost, and long-term adverse effects on arterial resistance and left ventricular remodeling. Since there has not been a large-scale, prospective, randomized

\footnotetext{
From Thoracic Aortic Surgery, Division of Cardiothoracic Surgery, Emory University School of Medicine, Atlanta, Ga.

Disclosures: The author reported no conflicts of interest.

The Journal policy requires editors and reviewers to disclose conflicts of interest and to decline handling or reviewing manuscripts for which they may have a conflict of interest. The editors and reviewers of this article have no conflicts of interest.

Received for publication Jan 22, 2021; revisions received Jan 22, 2021; accepted for publication Jan 25, 2021; available ahead of print Jan 30, 2021.

Address for reprints: Bradley G. Leshnower, MD, Division of Cardiothoracic Surgery, Emory University School of Medicine, 1365 Clifton Rd NE, Suite A2257, Atlanta, GA 30322 (E-mail: bleshno@emory.edu).

J Thorac Cardiovasc Surg 2023;165:14-5

$0022-5223 / \$ 36.00$

Copyright (c) 2021 by The American Association for Thoracic Surgery

https://doi.org/10.1016/j.jtcvs.2021.01.092
}

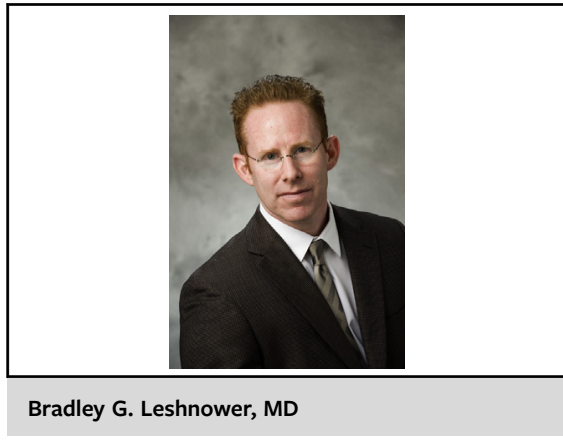

\section{CENTRAL MESSAGE \\ TEVAR for acute uncomplicated type $\mathrm{B}$ aortic dissection is a safe procedure with equivalent short- term outcomes to patients with acute complicated dissections.}

trial comparing TEVAR with OMT for uATBAD, physicians are left with retrospective, observational data to guide their treatment.

The report from the GREAT (Global Registry for Endovascular Aortic Treatment) registry in this month's Journal by Spinelli and colleagues ${ }^{4}$ examines the real-world early outcomes of TEVAR for the treatment of 102 patients with cATBAD and 70 with uATBAD with the Gore TAG and comfortable TAG grafts from 2010 to 2016. The data from the patients with cATBAD confirm TEVAR as the optimal therapy for this high-risk group. However, the real value of this report lies in the data from the uncomplicated patients. In this group, the 30-day, 1-, and 3-year mortality rates were $1.4 \%, 3.2 \%$, and $9.6 \%$, which are equivalent or superior to OMT data at similar time points from other reports in the literature. ${ }^{3,5}$ Furthermore, the aortic event-free survival was $77 \%$ and $71 \%$ at 1 and 3 years, respectively, an end point that includes the need for reintervention, stroke, spinal cord ischemia, aneurysm growth, retrograde dissection, or persistent false lumen entry flow. These data establish the perioperative safety of TEVAR for patients with uATBAD and demonstrate that TEVAR is noninferior to OMT in the short term. Unfortunately, the median follow-up in this study was brief ( 2 years), and there are very few data available to assess the efficacy of aortic remodeling, including changes in true and false lumen and total aortic diameters and the extent of false lumen thrombosis.

Given the poor long-term results with OMT and the growing body of data demonstrating the safety and efficacy 
of TEVAR in patients with UATBAD, endovascular therapy should become the primary therapy for all patients with UATBAD with favorable anatomy who are not at the extreme ends of the age spectrum. It is time to move forward; this is not a complicated decision.

\section{References}

1. Fattori R, Cao P, De Rango P, Czerny M, Evangelista A, Nienaber C, et al, Interdisciplinary expert consensus document on management of type $\mathrm{B}$ aortic dissection. J Am Coll Cardiol. 2013;61:1661-78.
2. Lou X, Chen EP, Duwayri YM, Veeraswamy RK, Jordan WD Jr, Zehner CA, et al The impact of thoracic endovascular aortic repair on long-term survival in type B aortic dissection. Ann Thorac Surg. 2018;105:31-9.

3. Nienaber CA, Kische S, Rousseau H, Eggebrecht H, Rehders TC, Kundt G, et al. Endovascular repair of type B aortic dissection: long-term results of the randomized investigation of stent grafts in aortic dissection trial. Circ Cardiovasc Interv. 2013;6:407-16

4. Spinelli D, Weaver FA, Azizzadeh A, Magee GA, Piffaretti G, Benedetto F, et al. Endovascular treatment of complicated versus uncomplicated acute type B aortic dissection. J Thorac Cardiovasc Surg. 2023;165:4-13.e1.

5. Iannuzzi JC, Stapleton SM, Bababekov YJ, Chang D, Lancaster RT, Conrad MF et al. Favorable impact of thoracic endovascular aortic repair on survival of patients with acute uncomplicated type B aortic dissection. J Vasc Surg. 2018;68: 1649-55.
See Article page 4.

\section{Commentary: The 2-step strategy}

\author{
Lorenzo Di Bacco, MD, ${ }^{\mathrm{a}}$ Mattia Glauber, $\mathrm{MD},{ }^{\mathrm{b}}$ and
} Antonio Miceli, $\mathrm{MD}, \mathrm{PhD}^{\mathrm{b}}$

According to current guidelines, complicated type B aortic dissection (TBAD) requires endovascular therapy. ${ }^{1}$ Nonetheless, the treatment of uncomplicated TBAD (uTBAD) remains controversial. ${ }^{1}$ In this setting, thoracic endovascular aortic repair (TEVAR) has gained consensus over time; however, its recommendation remains in class IIa due to the lack of clinical trials. ${ }^{1}$ Spinelli and colleagues ${ }^{2}$ add evidence on the safety, efficacy, and usefulness of TEVAR in uTBAD. Analyzing Gore's Global Registry for Endovascular Aortic Treatment Registry, the authors report comparable outcomes between patients with complicated TBAD and uTBAD in terms of mortality, aortic complications, and reinterventions. The rationale of applying TEVAR in the treatment of TBAD is to seal the intimal tear, allowing the true lumen expansion and reducing the tension of the false lumen (FL) to promote its thrombosis. Moreover, endovascular aortic repair should reduce the risk of aortic remodeling and aortic-related complications (eg, aneurysm

\footnotetext{
From the ${ }^{\mathrm{a} C a r d i a c}$ Surgery Unit, University of Brescia, ASST Spedali Civili, Brescia, Italy; and ${ }^{\mathrm{b}}$ Department of Minimally Invasive Cardiac Surgery, Istituto Clinico Sant'Ambrogio, Milan, Italy.

Disclosures: The authors reported no conflicts of interest.

The Journal policy requires editors and reviewers to disclose conflicts of interest and to decline handling or reviewing manuscripts for which they may have a conflict of interest. The editors and reviewers of this article have no conflicts of interest.

Received for publication Feb 2, 2021; revisions received Feb 2, 2021; accepted for publication Feb 3, 2021; available ahead of print Feb 12, 2021

Address for reprints: Antonio Miceli, MD, PhD, Department of Minimally Invasive Cardiac Surgery, Istituto Clinico Sant'Ambrogio, Via LG Faravelli 16, Milano, Italy (E-mail: antoniomiceli79@alice.it).

J Thorac Cardiovasc Surg 2023;165:15-6

$0022-5223 / \$ 36.00$

Copyright (C) 2021 by The American Association for Thoracic Surgery

https://doi.org/10.1016/j.jtcvs.2021.02.011
}

Check for updates

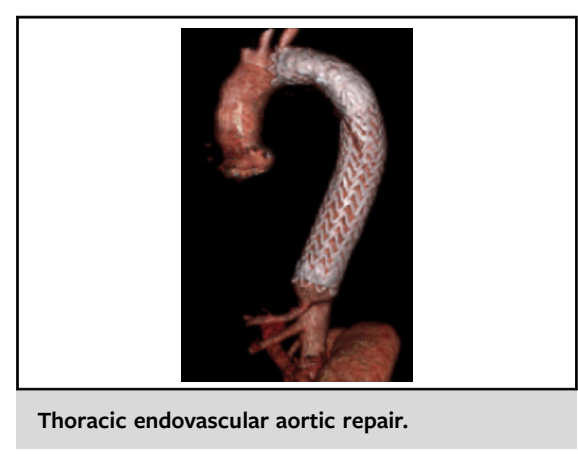

CENTRAL MESSAGE

Stratification of uncomplicated

type $\mathrm{B}$ aortic dissection and

correct timing for TEVAR im-

proves survival and prevents

aortic-related adverse events.

formation, rupture, and organ ischemia). ${ }^{3}$ Nevertheless, this procedure may be complicated by retrograde aortic dissection and the rate of reinterventions for endoleaks is around $24 \%$. ${ }^{4}$ The treatment of uTBAD with TEVAR should be carefully evaluated according to patient-specific presentation, weighting benefits and risks of the procedure. Reviewing preoperative computed tomographic images of uTBAD patients, Sailer and colleagues ${ }^{5}$ identified 5 risk factors: connective disorders, circumferential extension of FL, the maximal aortic diameter, FL outflow, and intercostal branches involved. Based on these characteristics, they were able to stratify patients in low, intermediate, or high risk for adverse events. Moreover, the concavity of the distal arch and entry tears $>10 \mathrm{~mm}$ were associated 